\title{
Familial Hypocalciuric Hypercalcemia and Neonatal Severe Hyperparathyroidism Effects of Mutant Gene Dosage on Phenotype
}

\author{
Martin R. Pollak, ** Yah-Huei Wu Chou, * Stephen J. Marx, Beat Steinmann," David E. C. Cole," \\ Maria Luisa Brandi, * " Socrates E. Papapoulos, "\# Fred H. Menko, "\# Geoffrey N. Hendy, "* \\ Edward M. Brown, * Christine E. Seidman, * and J. G. Seidman * \\ ${ }^{*}$ Department of Medicine, Brigham and Women's Hospital, and ${ }^{\ddagger}$ Department of Genetics and Howard Hughes Medical Institute, \\ Harvard Medical School, Boston, Massachusetts 02115; ${ }^{\$}$ Metabolic Diseases Branch, National Institute of Diabetes and Digestive and \\ Kidney Diseases, Bethesda, Maryland 20892; "Department of Pediatrics, University of Zurich, CH-8032 Zurich, Switzerland; \\ 'Departments of Pathology and Pediatrics, Dalhousie University, Halifax, B3J 3 G9 Canada; ** Department of Clinical Physiopathology, \\ University of Florence, 50139 Florence, Italy; ${ }^{\ddagger}$ Department of Endocrinology and Metabolic Diseases, University Hospital, 2333 AA \\ Leiden, The Netherlands; and ${ }^{\$}$ Department of Medicine, McGill University, Montreal, Quebec H3A 1A1, Canada
}

\begin{abstract}
Neonatal severe hyperparathyroidism is a rare life-threatening disorder characterized by very high serum calcium concentrations ( $>15 \mathrm{mg} / \mathrm{dl}$ ). Many cases have occurred in families with familial hypocalciuric hypercalcemia, a benign condition transmitted as a dominant trait. Among several hypothesized relationships between the two syndromes is the suggestion that neonatal severe hyperparathyroidism is the homozygous form of familial hypocalciuric hypercalcemia. To test this hypothesis, we refined the map location of the gene responsible for familial hypocalciuric hypercalcemia on chromosome 3q. Analyses in 11 families defined marker loci closely linked to the gene responsible for familial hypocalciuric hypercalcemia. These loci were then analyzed in four families with parental consanguinity and offspring with neonatal severe hyperparathyroidism. Each individual who was homozygous for loci that are closely linked to the gene responsible for familial hypocalciuric hypercalcemia had neonatal severe hyperparathyroidism. The calculated odds of linkage between these disorders of $>$ 350,000:1 (lod score $=5.56)$. We conclude that dosage of the gene defect accounts for these widely disparate clinical phenotypes; a single defective allele causes familial hypocalciuric hypercalcemia, while two defective alleles causes neonatal severe hyperparathyroidism. (J. Clin. Invest. 1994. 93:11081112.) Key words: gene dosage • chromosome $3 q \cdot$ consanguinity $\bullet$ hypercalcemia $\bullet$ hyperparathyroidism
\end{abstract}

\section{Introduction}

Familial hypocalciuric hypercalcemia $\left([\mathrm{FHH}]^{1}\right.$ also termed familial benign hypercalcemia) is generally an asymptomatic disorder characterized by modest elevation of serum calcium

Address correspondence to Martin R. Pollak, Department of Genetics, Harvard Medical School, EQRF Room 533, 200 Longwood Avenue, Boston, MA 02115.

Received for publication 16 August 1993 and in revised form 19 October 1993.

1. Abbreviations used in this paper: $\mathrm{FHH}$, familial hypocalciuric hypercalcemia; NSHPT, neonatal severe (primary) hyperparathyroidism.

J. Clin. Invest.

(C) The American Society for Clinical Investigation, Inc.

0021-9738/94/03/1108/05 $\$ 2.00$

Volume 93, March 1994, 1108-1112 concentration, relative hypocalciuria, and inappropriately normal parathyroid hormone levels. The condition is inherited as an autosomal dominant trait and the phenotype can be diagnosed soon after birth. While the penetrance of FHH approaches $100 \%$, affected individuals exhibit virtually none of the morbidity generally associated with hypercalcemia $(1,2)$. Physiologic and biochemical studies on individuals with FHH demonstrate abnormal responses of both the kidney and the parathyroid gland to calcium $(2,3)$. Although the precise genetic defect is unknown, linkage analyses have demonstrated that the disease locus in most FHH families is located on the long arm of chromosome $3(4,5)$. In one family, an FHH locus maps to chromosome $19 \mathrm{p} 32$ (5).

Neonatal severe hyperparathyroidism ([NSHPT] also termed neonatal familial primary hyperparathyroidism) is a rare disease characterized by marked hypercalcemia (often $>20 \mathrm{mg} / \mathrm{dl}$ ), skeletal demineralization, parathyroid hyperplasia, respiratory distress, and hypotonia $(6,7)$. While severe parathyroid hyperplasia appears to be central to this metabolic disturbance, its cause is unknown. Without parathyroidectomy, NSHPT is generally fatal, though rare cases of less severely affected neonates have been successfully managed medically $(8,9)$.

Since the initial report of NSHPT in 1947 (10) and FHH in 1972 (11), physicians have frequently recognized familial coincidence of these two disorders $(6,12-15)$. Several hypotheses have been offered to explain this observation: (a) NSHPT may represent an extreme phenotype that occurs within the spectrum of clinical severity in $\mathrm{FHH} ;(b)$ an unidentified protein(s) may interact with the mutationally altered FHH gene product to cause NSHPT; $(c)$ because NSHPT has been reported in the offspring of fathers with FHH and unaffected mothers, NSHPT may represent in utero development of severe secondary hyperparathyroidism in an FHH child in response to normocalcemia in the mother or to uniparental disomy; and $(d)$ because NSHPT has occurred in several offspring of consanguineous marriages between $\mathrm{FHH}$ parents, it may be the homozygous form of FHH.

Identification of DNA markers linked to FHH loci on chromosome $3 q(4)$ and $19 p(5)$ permits definition of the genetic relationship between FHH and NSHPT. We studied seven additional FHH families, and demonstrated that the predominant gene defect responsible for FHH maps to chromosome $3 q 2$. Four of these families had consanguineous marriages and affected NSHPT offspring. Analyses of these demonstrate that NSHPT also maps to chromosome $3 \mathrm{q} 2$, and that it results from homozygosity of a mutated FHH gene. 


\section{Methods}

Clinical studies. Consent was obtained from all participants or their guardians in accordance with standards established by the local institutions. Measurements of total calcium concentration in all families were made by colorimetric assays.

11 unrelated families with $\mathrm{FHH}$ were studied. The diagnosis of FHH was based on the finding of asymptomatic hypercalcemia accompanied by normal levels of PTH (2). Previous studies in four families (A, B, C, D) had showed linkage of FHH to chromosome 3q (4). Three additional FHH families ( $\mathrm{J}, \mathrm{N}$, and $\mathrm{P}$ ) and four families (described below) with both FHH and NSHPT were studied to further examine the possibility of genetic heterogeneity. Clinical evaluations of families $\mathrm{J}, \mathrm{N}$, and $\mathrm{P}$ were previously reported $(13,14,16)$.

Four FHH families (E, I, Q, S; Fig. 1) had at least one NSHPT proband who was the product of a consanguineous marriage. The diagnosis of NSHPT was made on the basis of marked hypercalcemia presenting shortly after birth and marked elevation of serum PTH levels (Table I). Families E, I, and S are of Turkish, European Jewish, and Canadian descent, respectively. Detailed clinical and laboratory descriptions of these families have been reported previously $(13,15,17$, 18). Family $Q$ lives in Italy. NSHPT was diagnosed in individual IV-1 (Fig. 1) at birth. Serum calcium was $19 \mathrm{mg} / \mathrm{dl}$ and serum PTH level $>800 \mathrm{pg} / \mathrm{ml}$ (normal $=10-65$; Allegro immunoradiometric assay [Nichols Institute], which detects only intact PTH). Total parathyroidectomy was performed. His calcium levels progressively declined to the subnormal range. He is currently $3 \mathrm{yr}$ old and maintained on vitamin D.

Genetic studies. DNA was extracted from peripheral lymphocytes or EBV-transformed lymphoblastoid cell lines as described previously $(19,20)$. Genotypes of family members were defined with polymorphic markers for loci D3S1303, D3S1267, and D3S1269 on chromosome $3 q 2$ using methods described previously (4). In all families, twopoint analyses were performed using the MLINK program as described $(4,21)$, with the penetrance of FHH assumed to be $100 \%$. Lod scores $>1.3$ (odds $>20: 1$ ) were considered evidence of linkage to the FHH locus because only closely linked loci were analyzed.

Linkage analyses for NSHPT were performed in families E, I, Q, and $S$, using the computer program MLINK, with a disease penetrance of $100 \%$. Haplotype frequencies, rather than allele frequencies, were used for lod score calculations. Haplotypes were defined by alleles at D3S1303, D3S1267, and D3S1269 for all surviving members of each NSHPT family and for all members of FHH families A, B, C, and D. The frequency of a given haplotype equals the ratio of independent occurrences of that haplotype divided by the sum of independent occurrences of all haplotypes in the population. An independent occurrence is defined as a haplotype that was brought into the family by an ancestor or an unrelated spouse. A total of 82 independent occurrences were observed among 67 different haplotypes. Haplotype frequencies of 0.049 (family E) and 0.012 (family I, Q, and S) were used for lod score calculations.

\section{Results}

Genetic analyses of $\mathrm{FHH}$. FHH has been shown to segregate with polymorphic loci on chromosome 3q21-24 in four large families (A, B, C, D). Two recent genetic maps of the human genome $(22,23)$ have identified 10 polymorphic loci within 20 cM of this FHH locus. The genotypes of all members of families A, B, C, and D were defined at these 10 loci (data not shown ). By assessing recombination events between $\mathrm{FHH}$ and each locus, the FHH gene was located in the region between loci D3S1303 and D3S1267 (Fig. 2).

Three loci D3S1303, D3S1267, and D3S1269 were then used to assess genetic heterogeneity of FHH in seven additional families. Six families (J, N, P, E, I, S), three of whom also had
NSHPT, provided sufficient information to conclude that FHH was linked to this locus (Table II). The combined maximum lod score in these 10 families is $35.64(\theta=0.01$ from D3S1303). While the maximum lod score in family $Q$ favored linkage, this family was too small to independently prove linkage of $\mathrm{FHH}$ at this locus (maximum lod score $=0.86$; Table II). In the four families with both FHH and NSHPT, the combined likelihood that $\mathrm{FHH}$ is linked to chromosome 3q21-24 is $>4,000,000: 1($ lod score $=6.66$; Table II $)$.

Genetic analyses of NSHPT. The inheritance of NSHPT at the same three loci (D3S1303, D3S1267, and D3S1269) in families E, I, Q, and S was also studied. Lod scores were calculated to compare the likelihood of the autosomal recessive inheritance of NSHPT linked to the FHH locus hypothesis versus the likelihood of random association between the NSHPT and FHH loci in these families. These calculations depend on the haplotype frequency in the relevant ethnic group for each family. Because this information is unavailable, lod scores were calculated assuming a low haplotype frequency, a high haplotype frequency and a haplotype frequency estimated from our study population (Methods).

If the haplotype coinherited with NSHPT in the families E, $\mathrm{I}, \mathrm{Q}$, and $\mathrm{S}$ is very rare (frequency $=0.001$ ), then the ratio of the likelihood that NSHPT and the FHH locus are genetically linked to the likelihood that both were inherited by chance is $>3,000,000: 1$ (lod score $=6.53)$. By contrast, if the frequency of each of these haplotypes is $10 \%$, then the likelihood of linkage between NSHPT and FHH is 5,500:1 (lod score $=3.74)$. Using a haplotype frequency estimated from our study population the likelihood of linkage between NSHPT and FHH is $>350,000: 1($ lod score $=5.56$, Table II $)$.

The haplotypes found in NSHPT patients in families E, I, $\mathrm{Q}$, and $\mathrm{S}$ are unique, suggesting that the disease-causing mutation(s) either arose independently in each family or that any common ancestor to these families is very remote. Two identical haplotypes were present in each individual with NSHPT, demonstrating homozygosity of this locus (Fig. 1). Since this haplotype also segregates with FHH in each family, we conclude that the NSHPT phenotype results when an individual inherits two FHH alleles.

\section{Discussion}

Using polymorphic markers on chromosome $3 \mathrm{q} 2$, we provide evidence of a predominant locus for FHH (references 4 and 5 and Table II). Genetic analyses of FHH families with NSHPT demonstrate that NSHPT can be transmitted as an autosomal recessive disorder tightly linked to the $\mathrm{FHH}$ locus (odds $>350,000: 1$ ) on chromosome 3q2. We conclude that the clinical phenotype associated with two copies of a defective $\mathrm{FHH}$ gene is NSHPT.

Since the haplotype defined in these studies was always homozygous in individuals with NSHPT and always heterozygous in individuals with FHH, the hypothesis that NSHPT is an extreme phenotype resulting from a single $\mathrm{FHH}$ mutation appears invalid. Similarly, if an unidentified protein(s) was required to interact with the mutationally altered $\mathrm{FHH}$ gene product to cause NSHPT, it is unlikely that this would occur only in offspring who are homozygous for the FHH haplotype. Rather, these studies provide genetic evidence that severe lifethreatening NSHPT results from inheritance of two defective FHH alleles. 
Family E

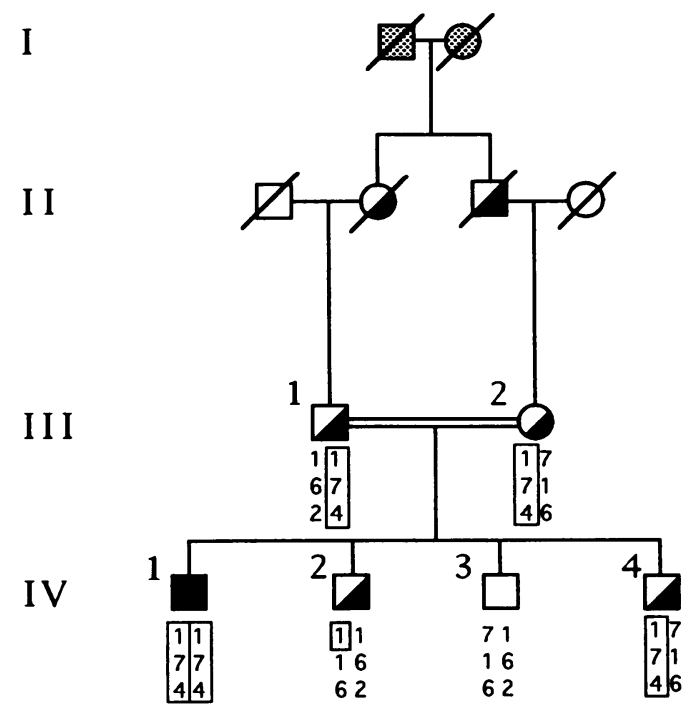

Family I

I

I I

I I I

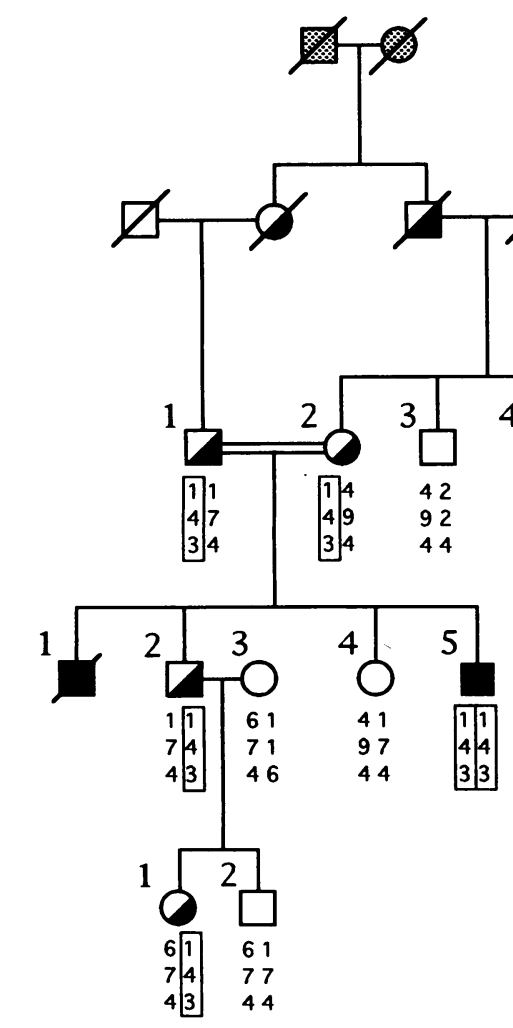

Family Q

I

I I

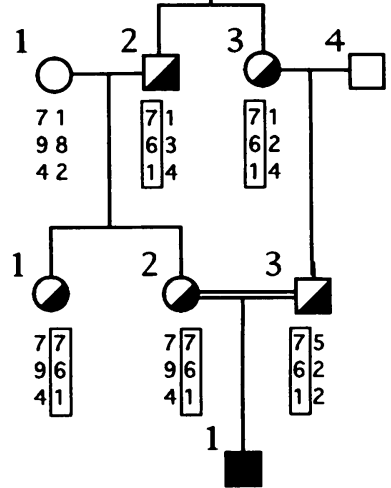

IV

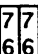

Family S

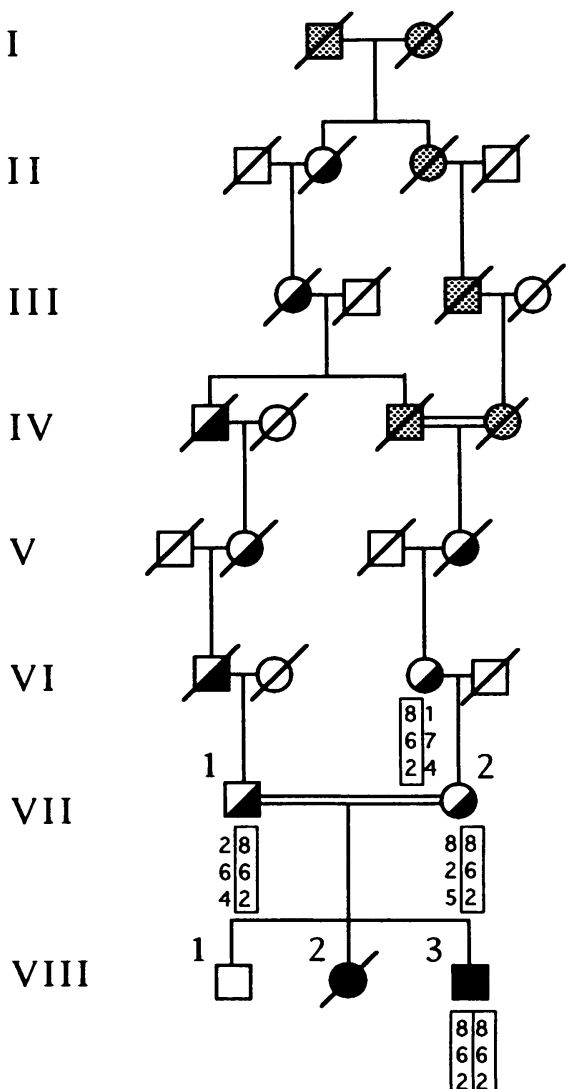

Figure 1. Pedigrees of four NSHPT families. Individuals are represented by squares (male), circles (female), and slashes (deceased), and they are identified by generation and pedigree numbers. Consanguinous marriages are shown as double lines. Clinical status is indicated by open symbols (unaffected), half-filled symbols (FHH), filled symbols (NSHPT), and speckled symbols (unknown), and described in Table I and Methods. The genotypes (defined by loci D3S1303, D3S1267, and D3S1269, Fig. 2) of individuals available for study are shown. The haplotype associated with FHH is boxed. 
Table I. Clinical Evaluations of NSHPT Families

\begin{tabular}{|c|c|c|c|c|c|}
\hline Individual & Sex & Calcium & Ionized $\mathrm{Ca}^{++}$ & IPTH & Diagnosis \\
\hline & & $m g / d l$ & $m M$ & $p g / m l$ & \\
\hline \multicolumn{6}{|l|}{ Family E } \\
\hline III-1 & $\mathbf{M}$ & 11.3 & & & $\mathrm{FHH}$ \\
\hline III-2 & $\mathrm{F}$ & 11.7 & & & $\mathrm{FHH}$ \\
\hline IV-1 & $\mathbf{M}$ & $15.5^{*}$ & & $630^{\ddagger}$ & NSHPT \\
\hline IV-2 & $\mathbf{M}$ & 12.3 & & & $\mathrm{FHH}$ \\
\hline IV-4 & $\mathbf{M}$ & 12.2 & & & $\mathrm{FHH}$ \\
\hline \multicolumn{6}{|l|}{ Family I } \\
\hline III-1 & $\mathbf{M}$ & 11.0 & & & $\mathrm{FHH}$ \\
\hline III-2 & $\mathbf{F}$ & 11.1 & & & FHH \\
\hline III-5 & $\mathrm{F}$ & 10.6 & & & FHH \\
\hline IV-1 & $\mathbf{M}$ & $22^{*}$ & & & NSHPT $^{\S}$ \\
\hline IV-2 & $\mathbf{M}$ & 11.5 & & & FHH \\
\hline IV-5 & $\mathbf{M}$ & $29^{*}$ & & & NSHPT \\
\hline V-1 & $\mathrm{F}$ & 11.7 & & & FHH \\
\hline \multicolumn{6}{|l|}{ Family Q } \\
\hline II-2 & $\mathbf{M}$ & 10.9 & 1.47 & 14 & FHH \\
\hline II-3 & $\mathrm{F}$ & 10.8 & 1.40 & 25 & FHH \\
\hline III-1 & $\mathrm{F}$ & 10.5 & 1.37 & 36 & FHH \\
\hline III-2 & $\mathrm{F}$ & 11.0 & 1.45 & 37 & $\mathrm{FHH}$ \\
\hline III-3 & $\mathbf{M}$ & 10.9 & 1.40 & 28 & FHH \\
\hline IV-1 & $\mathrm{F}$ & $19^{*}$ & & $>800$ & NSHPT \\
\hline \multicolumn{6}{|l|}{ Family $\mathrm{S}$} \\
\hline VI-1 & $\mathrm{F}$ & 11.2 & 1.38 & & FHH \\
\hline VII-1 & $\mathbf{M}$ & 10.8 & & & $\mathrm{FHH}$ \\
\hline VII-2 & $\mathrm{F}$ & 10.8 & 1.34 & & $\mathrm{FHH}$ \\
\hline VIII-2 & $\mathrm{F}$ & & & & NSHPT $^{\S}$ \\
\hline VIII-3 & $\mathbf{M}$ & 15.2 & 1.54 & 1,405 & NSHPT \\
\hline
\end{tabular}

* Values measured before parathyroidectomy (E-IV-1, Q-IV-1, and I-IV-5), death (I-IV-1), or at 11 mo of age (S-VII-3). iPTH, intact parathyroid hormone; normal $=10-65 \mathrm{pg} / \mathrm{ml}$. ${ }^{\ddagger}$ Carboxyl terminal PTH levels (ng/ml); normal $<40 \mathrm{ng} / \mathrm{ml}$. ${ }^{\S}$ Died shortly after birth.

We speculate that NSHPT individuals in FHH families without consanguinity may be double heterozygotes, having inherited different mutated alleles of the FHH gene on chromosome $3 q$ from each parent. While we can not exclude the possibility that some individuals with NSHPT may be heterozy-

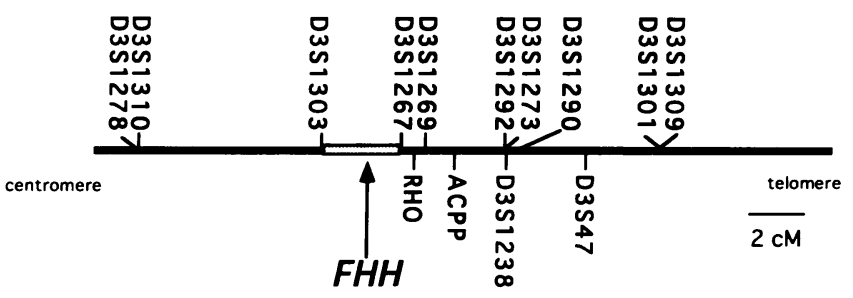

Figure 2. Genetic linkage between FHH, NSHPT and chromosome $3 q 2$ loci. Genetic map of loci flanking the FHH gene on chromosome 3q2. The order of DNA loci were taken from Weissenbach et al. (22), and the NIH/CEPH Collaborative Mapping Group (23). Recombination events defined by analyses of families $A, B, C$, and $D$ were used to integrate published maps (data not shown) and to identify the most likely region for the FHH gene (indicated).
Table II. Linkage of FHH, NSHPT, and D3S1303 in 11 Families

\begin{tabular}{lcccccc}
\hline & \multicolumn{3}{c}{$\begin{array}{c}\text { Number of } \\
\text { affected members }\end{array}$} & & \multicolumn{2}{c}{ Lod scores* } \\
\cline { 3 - 3 } \cline { 5 - 6 } Family & Ref. & FHH & NSHPT & & FHH & NSHPT \\
\hline A & 4 & 23 & & 5.36 & \\
B & 4 & 16 & & & 4.52 & \\
C & 4 & 37 & & 7.23 & \\
D & 4 & 20 & & 3.51 & \\
J & 14 & 8 & & 1.38 & \\
N & 12 & 17 & & 3.34 & \\
P & 16 & 22 & & 4.50 & \\
E & 15 & 6 & 1 & 1.32 & 1.37 \\
I & 13 & 7 & 2 & 3.18 & 1.41 \\
Q & - & 5 & 1 & 0.86 & 0.89 \\
S & 18 & 7 & 2 & 1.30 & 1.89 \\
& & & & & \\
\hline
\end{tabular}

* Lod scores were calculated (Methods) at $\theta=0.01$ from D3S1303, the most likely location of the FHH gene. The FHH lod scores were calculated ignoring the individuals with NSHPT; the NSHPT lod scores included all individuals.

gotes for mutated alleles on both chromosome $3 q$ and chromosome 19p, the low incidence of FHH in the population and the infrequent finding of genetic heterogeneity (only 1 of $16 \mathrm{FHH}$ families maps to $19 p$ (references 4 and 5 and families studied here) makes this an unlikely possibility. NSHPT that occurs in families in which only one parent has clinical findings of $\mathrm{FHH}$ may reflect incomplete penetrance, unrecognized FHH, uniparental disomy, or de novo mutation in the unaffected allele. While current laboratory techniques are quite sensitive for detecting even mild hypercalcemia, some individuals with $\mathrm{FHH}$ has been reported to have only intermittent hypercalcemia ( 2 , 12). Further, affected individuals in the one family with FHH that maps to chromosome $19 p$ were noted to have more mild hypercalcemia than individuals with FHH because of mutations on chromosome 3q. If specific mutations in either locus cause very mild or only intermittent hypercalcemia that is clinically unrecognized, a phenotype (NSHPT) might be apparent only in the homozygous or double heterozygous state.

Recent studies (24) have suggested that heterozygous individuals with FHH exhibit a mild increase in the set point of their parathyroid glands for calcium (the $\mathrm{Ca}^{++}$concentration producing half of the maximal inhibition of parathyroid hormone release). In two cases $(25,26)$ in which the parathyroid tissue from individuals with NSHPT was studied in vitro, there was a much more marked increase in the set point for $\mathrm{Ca}^{++}$. We speculate that one abnormal allele of the FHH gene produces mildly abnormal $\mathrm{Ca}^{++}$-regulated parathyroid hormone secretion, while parathyroid glands expressing two mutant alleles are only responsive to severely hypercalcemic levels of $\mathrm{Ca}^{++}$. These results are consistent with the FHH gene playing an important role in the sensing of extracellular $\mathrm{Ca}^{++}$by the parathyroid gland.

\section{Acknowledgments}

We are indebted to families members, Mr. Mohammed Miri, and Ms. Mia Ryan; without their invaluable assistance, these studies would have been impossible. 
This study was supported by grants from the National Institutes of Health (DK02138, M. R. Pollak; HL-41474, C. E. Seidman; DK36796 and DK41415, E. M. Brown), the Howard Hughes Medical Foundation (Y.-H. Wu Chou and J. G. Seidman), and the American Heart Association (C. E. Seidman).

\section{References}

1. Law, W., and H. Heath III. 1985. Familial benign hypercalcemia (hypocalciuric hypercalcemia). Clinical and pathogenetic studies in 21 families. Ann. Int. Med. 102:511-519.

2. Marx, S. J., M. F. Attie, M. A. Levine, A. M. Spiegel, R. W. Downs, Jr., and R. D. Lasker. 1981. The hypocalciuric or benign variant of familial hypercalcemia: clinical and biochemical features in fifteen kindreds. Medicine (Baltimore). 60:397-412.

3. Attie, M. F., J. R. Gill, Jr., J. L. Stock, A. M. Spiegel, R. W. Downs, Jr., M. A. Levine, and S. J. Marx. 1983. Urinary calcium excretion in familial hypocalciuric hypercalcemia. Persistence of relative hypocalciuria after induction of hypoparathyroidism. J. Clin. Invest. 72:667-676.

4. Chou, Y.-H. W., E. M. Brown, T. Levi, G. Crowe, A. B. Aktkinson, H. J. Arnqvist, G. Toss, G. E.-H. Fuleihan, J. G. Seidman, and C. E. Seidman. 1992. The gene responsible for familial hypocalciuric hypercalcemia maps to chromosome 3q in four unrelated families. Nature Genetics. 1:295-299.

5. Heath, H. III, C. E. Jackson, B. Otterud, and M. F. Leppert. 1993. Genetic linkage analyses in familial benign (hypocalciuric) hypercalcemia: evidence for locus heterogeneity. Am. J. Hum. Genet. 53:193-200.

6. Blair, J. W., and R. Carachi. 1991. Neonatal primary hyperparathyroidism. A case report and review of the literature. Eur. J. Pediatr. Surg. 1:110-114.

7. Ross, A. J., A. Cooper, M. F. Attie, and H. C. Bishop. 1986. Primary hyperparathyroidism in infancy. J. Pediatr. Surg. 6:493-499.

8. Harris, S. S., and A. J. D'Ercole. 1989. Neonatal hyperparathyroidism: the natural course in the absence of surgical intervention. Pediatrics. 83:53-56.

9. Page, L. A., and J. E. Haddow. 1987. Self-limited neonatal hyperthyroidism in familial hypocalciuric hypercalcemia. J. Pediatr. 111:261-264.

10. Pratt, E. L., B. B. Beren, and E. B. D. Neuhauser. 1947. Hypercalcaemia and ideopathic hyperplasia of the parathyroid glands in an infant. J. Pediatr. 30:388-399.

11. Foley, T. P., H. C. Harrison, C. D. Arnaud, H. E. Harrison. 1972. Familial benign hypercalcaemia. J. Pediatr. 81:1060-1067.

12. Marx, S. J., M. F. Attie, A. M. Spiegel, M. A. Levine, R. D. Lasker, and M. Fox. 1982. An association between neonatal severe primary hyperparathyroidism and familial hypocalciuric hypercalcemia in three kindreds. N. Engl. J. Med. 306:257-264.

13. Marx, S. J., D. Fraser, and A. Rapoport. 1985. Familial hypocalciuric hypercalcemia. Mild expression of the gene in heterozygotes and severe expression in homozygotes. Am. J. Med. 78:15-22.

14. Marx, S. J., A. M. Spiegel, E. M. Brown, and G. D. Aurbach. 1977. Family studies in patients with primary parathyroid hyperplasia. Am. J. Med. 62:698706.

15. Steinmann, B., H. E. Gnehm, V. H. Rao, H. P. Kind, and A. Prader. 1984. Neonatal severe primary hyperparathyroidism and alkaptonuria in a boy born to related parents with familial hypocalciuric hypercalcemia. Helv. Paediatr. Acta. 39:171-86.

16. Menko, F. H., O. L. M. Bijvoet, J. L. H. H. Fronen, L. M. Sandler, S. Adami, J. L. H. O'Riordan, W. Schopman, G. Heynen, and W. Blomen-Kuneken. 1983. Familial benign hypercalcemia, study of a large family. Q. J. Med. 206:120-140.

17. Hillman, D. A., C. R. Scriver, S. Pedvis, and I. Shragovitch. 1964. Neonatal familial hyperparathyroidism. N. Engl. J. Med. 270:483-90.

18. Cole, D. E. C., C. R. Forsythe, J. M. Dooley, E. B. Grantmyre, and S. R. Salisbury. 1990. Primary neonatal hyperparathyroidism: a devastating neurodevelopmental disorder if left untreated. J. Craniofacial Genet. Dev. Biol. 10:20514.

19. Anderson, M. A., and J. F. Gusella. 1984. Use of cyclosporin A in establishing Epstein-Barr Virus transformed human lymphoblastic cell lines. In Vitro. 20:856-858

20. Treco, D. 1992. Preparation and analysis of DNA. In Current Protocols in Molecular Biology. F. M. Ausubel, R. Brent, R. E. Kingston, D. D. Moore, J. Smith, J. G. Seidman, and K. Struhl editors. Greene Publishing, New York. 2.1.1-2.1.7.

21. Ott, J. 1985. Analysis of Human Linkage. The Johns Hopkins University Press, Baltimore.

22. Weissenbach, J., G. Gyapay, C. Dib, A. Vignal, J. Morisette, P. Millawwear, G. Vaysseix, and M. Lathrop. 1992. A second-generation linkage map of the human genome. Nature (Lond.). 359:794-801.

23. NIH/CEPH Collaborative Mapping Group. 1992. A comprehensive genetic linkage map of the human genome. Science (Wash. DC). 258:67-86.

24. Khosla, S., P. R. Ebeling, A. F. Firek, N. N. Burritt, P. C. Kao, and H. Heath III. 1993. Calcium infusion suggests a "set-point" abnormality of parathyroid gland function in familial benign hypercalcemia and more complex disturbances in primary hyperparathyroidism. J. Clin. Endocrinol. \& Metab. 76:715720.

25. Cooper, L., J. Wertheimer, R. Levey, E. Brown, M. LeBoff, R. Wilkinson, and C. Anast. 1986. Severe primary hyperparathyroidism in a neonate with two hypercalcemic parents: management with parathyroidectomy and heterotopic autotransplantation. Pediatrics. 78:263-268.

26. Marx, S. J., R. D. Lasker, E. M. Brown, L. A. Fitzpatrick, N. B. Sweezey, R. B. Goldbloom, D. A. Gillis and D. E. C. Cole. 1986. Secretory dysfunction in parathyroid cells from a neonate with severe primary hyperparathyroidism. $J$. Clin. Endocrinol. \& Metab. 62:445-449. 